\title{
Studies on the influence of different fly ashes and Portland cement on early hydration of calcium aluminate cement
}

\author{
Barbara Pacewska • Iwona Wilińska • \\ Mariola Nowacka
}

Received: 3 September 2010/Accepted: 7 April 2011/Published online: 1 May 2011

(C) The Author(s) 2011. This article is published with open access at Springerlink.com

\begin{abstract}
The influence of three mineral additives, i.e. fly ashes from pulverized combustion and from fluidized combustion of hard coal as well as Portland cement, on early hydration (up to 28th day) of calcium aluminate cement was investigated. Cement pastes containing 0, 5 and $25 \mathrm{wt} \%$ of additives were studied by the use of calorimetry, thermal analysis and infrared spectroscopy methods. It was confirmed that hydration of calcium aluminate cement is closely dependent on the type of addition and its amount. The influence of additives of different properties on cement hydration was discussed basing on received results and other literature reports.
\end{abstract}

Keywords Calcium aluminate cement · Fly ash · Portland cement $\cdot$ Heat of hydration · TG-DTA · IR

\section{Introduction}

Calcium aluminate cements are hydraulic binders of special properties and applications. They are mainly applied in production of fire-resistant materials but this kind of cement is also useful in cases when concreting in temperatures below zero, higher resistance for sulphate aggression or fast increase of strength are required. Moreover calcium aluminate cement may be a component of ready for use mixtures for special applications in building works, for example, quick hardening or expansive binders.

B. Pacewska $(\bowtie) \cdot$ I. Wilińska · M. Nowacka Faculty of Civil Engineering, Mechanics and Petrochemistry, Institute of Chemistry, Warsaw University of Technology, Lukasiewicza 17 St., 09-400 Plock, Poland

e-mail: bpacewska@pw.plock.pl
Calcium aluminate cements are expensive materials, especially in comparison with Portland cement. That is why, it is aimed at reduction of amount of calcium aluminate cement in composite or its partial substitution by other, cheaper materials. Despite high price of calcium aluminate cements, their application might be potentially greater if one succeed in eliminating danger of strength reduction being a consequence of conversion of aluminate.

Calcium aluminate cements are especially sensitive to changes of conditions of hardening. It causes that their properties, such as rate of hardening, strength, etc., change inter alia in presence of additives. Research works concerning mixing of calcium aluminate cement with different fine-grained additives such as waste materials (e.g. silica fume [1, 2], fly ash [1-3], slag [4], spent aluminosilicate [5]) as well as other types of cements (e.g. Portland cement $[6,7])$ have been undertaken. In this way one may obtain a new binder of improved and/or changed properties. It is the effect of action of active additives that influence physical and chemical processes and arising products of hydration.

The main products of hydration of calcium aluminate cement at ambient temperature $\left(20-25^{\circ} \mathrm{C}\right)$ are hydrated hexagonal calcium aluminates type of $\mathrm{CAH}_{10}$ and $\mathrm{C}_{2} \mathrm{AH}_{8}$ as well as aluminium hydroxide $\mathrm{AH}_{3}$ (abbreviations used in cement chemistry and thereby in this work: $\mathrm{C}-\mathrm{CaO}$, $\mathrm{A}-\mathrm{Al}_{2} \mathrm{O}_{3}, \mathrm{H}-\mathrm{H}_{2} \mathrm{O}, \mathrm{S}-\mathrm{SiO}_{2}, \mathrm{c}-\mathrm{CO}_{2}$ ). The hexagonal hydrates, $\mathrm{CAH}_{10}$ and $\mathrm{C}_{2} \mathrm{AH}_{8}$, are metastable products. They inevitably convert with time or at higher temperature and in presence of humidity into cubic product $\mathrm{C}_{3} \mathrm{AH}_{6}$ and $\mathrm{AH}_{3}$. Strength of hardened cement material decreases as the effect of this conversion [8].

Some additives of pozzolanic or hydraulic properties, replacing part of cement in the material, are proposed to reduce hydrate conversion and its negative effects. In cement paste, reactive silica is released from these 
materials and then it reacts with components of the system. Phase $\mathrm{C}_{2} \mathrm{ASH}_{8}$ arises in this process. Some other $\mathrm{C}-\mathrm{A}-\mathrm{S}-$ $\mathrm{H}$ phases may also be formed, as it was observed by authors of work [9]. Arising of C-A-S-H type phases may be an alternative reaction way for $\mathrm{C}_{3} \mathrm{AH}_{6}$ forming during conversion. One of mechanism of additive action is proposed as follow [1]: silica released from the additive reacts initially with calcium aluminates to produce $\mathrm{C}_{2} \mathrm{ASH}_{8}$. In this way the formation of $\mathrm{C}_{2} \mathrm{AH}_{8}$ and subsequently its conversion to $\mathrm{C}_{3} \mathrm{AH}_{6}$ are avoided. However, in literature reports one may find that some researchers do not agree whether the total prevention of conversion in this way is possible. Mechanism of action of pozzolanic and hydraulic additives in aluminate cement system and their role in conversion process is not fully explained yet. Thus, such investigations should be continued.

A lot of research works have been devoted to introduction of fly ash into hydrating aluminate cement system [1-3]. These works mainly relate to the influence of different fly ashes coming from conventional technologies of combustion on hydration of cement and properties of the composite. In literature there are no research works found devoted to introduction of fly ash from fluidized combustion of coal into hydrating aluminate cement system. This type of fly ash exhibits different properties in comparison with the ashes coming from conventional methods of combustion. It is an effect of lower temperature of combustion (on average about $850{ }^{\circ} \mathrm{C}$ ). Fluidized fly ash is characterized by porous grains and, in contrast to conventional fly ash, it usually does not include glass or spherical grains. In composition of fluidized fly ash one may find: mainly dehydrated aluminosilicates, quartz, calcium compounds in the form of $\mathrm{CaO}, \mathrm{Ca}(\mathrm{OH})_{2}$ and $\mathrm{CaCO}_{3}$ as well as anhydrite or gypsum from flue-gas desulphurization, and also non-combusted coal [10]. In the presence of $\mathrm{Ca}^{2+}$ ions, fluidized fly ash exhibits higher pozzolanic activity than conventional fly ash [11]. One may expect that, for the sake of its chemical composition, fluidized fly ash will react in hydrating aluminate cement system in similar way as Portland cement. Thereby, fluidized fly ash may be considered as potential additive limiting the aluminate conversion (like conventional fly ash) as well as substitute of Portland cement in quickly hardening or expansive binder.

The aim of this work was investigation of early hydration (up to 28th day) of calcium aluminate cement in the presence of different additives. The action of fly ash from fluidized combustion of hard coal, as a new type of additive, in aluminate cement paste was studied in comparison with fly ash from pulverized combustion and Portland cement. The results presented in this work concern avoidance of conversion of aluminates and possibilities of usage of industrial waste in binders for special applications.

\section{Experimental}

Grey calcium aluminate cement "Górkal 40", produced by Górka Cement Sp. z o.o (Poland), was used as main component of the samples. For this cement the content of components recalculated into oxides is (mass $\%$ ): $\mathrm{Al}_{2} \mathrm{O}_{3}>40 \%$, $\mathrm{CaO}>36 \%, \mathrm{SiO}_{2}<4 \%, \mathrm{Fe}_{2} \mathrm{O}_{3}$ approximately $14 \%$ and mineralogical composition is: $\mathrm{CA}$ as a basic phase and $\mathrm{C}_{4} \mathrm{AF}$, $\mathrm{C}_{12} \mathrm{~A}_{7}$ and $\mathrm{C}_{2} \mathrm{AS}$ as accompanying phases (according to product description given by producer [12]).

Three types of inorganic additives were used: two kinds of fly ashes from different technology of combustion of hard coal and Portland cement type of CEM I 32.5 R. Fly ash from fluidized combustion (mean temperature of combustion about $850{ }^{\circ} \mathrm{C}$, calcium sorbent added for fluegas desulphurization) of hard coal was further signified in short as fluidized fly ash. Fly ash from conventional, pulverized combustion (temperature above $1000^{\circ} \mathrm{C}$ ) was signified as pulverized fly ash. Approximately, the ashes oxide chemical composition (the main components) was the following: for fluidized fly ash $55 \% \mathrm{SiO}_{2}, 16 \% \mathrm{Al}_{2} \mathrm{O}_{3}$, $5 \% \mathrm{Fe}_{2} \mathrm{O}_{3}, 10 \% \mathrm{CaO}, 5 \% \mathrm{SO}_{3}$ and for pulverized fly ash $50 \% \quad \mathrm{SiO}_{2}, 20 \% \mathrm{Al}_{2} \mathrm{O}_{3}, 7 \% \mathrm{Fe}_{2} \mathrm{O}_{3}, 5 \% \mathrm{CaO}, 1 \% \mathrm{SO}_{3}$ (mass\% in all cases).

The studied samples were cement pastes with the additions (0, 5 and 25 mass \% of additive in the mass of dry binder). The water/(cement + additive) ratio was 0.5 . Early hydration was studied during first $48 \mathrm{~h}$ (external temperature was $25^{\circ} \mathrm{C}$ ) by means of differential BMR calorimeter constructed at the Institute of Physical Chemistry of Polish Academy of Science. The results were calculated using computer software [13]. Thermal analysis and infrared absorption measurements were carried out for the cement pastes after 2nd and 28th day of hydration. Samples for these measurements were hydrated in sealed bags at temperature $22{ }^{\circ} \mathrm{C}$ during first 3 weeks and then at $25-30{ }^{\circ} \mathrm{C}$. At the appointed time, hydration was stopped by the use of acetone. SDT 2960 Thermoanalyser, produced by TaInstruments (heating rate $10{ }^{\circ} \mathrm{C} / \mathrm{min}$, mass of sample: 9-13 mg, nitrogen atmosphere) and FTIR spectrophotometer Genesis II, produced by Mattson $\left(4000-400 \mathrm{~cm}^{-1}\right.$, sample preparation-pelletizing with $\mathrm{KBr}$ ) were used.

\section{Results and discussion}

\section{Calorimetric measurements}

Calorimetry is a good method for studies on cement hydration during its first hours of action when chemical and physical processes occur most intensively. This technique bases on continuous measurements of heat released in time, starting from the addition of water into the dry binder. 
Results of these measurements for calcium aluminate cement paste containing different additives are presented in Fig. 1. Main effects of heat releasing are observed up to $24 \mathrm{~h}$, that is why this period was only presented in the figure.

The course of calorimetric curves is closely related to the chemical and physical processes occurring in the system. During first minutes after addition of water quick release of relatively small amount of heat is observed. This effect can be attributed to the wetting of binder grains, their superficial dissolving and the beginning of hydration processes. $\mathrm{Ca}^{2+}$ and $\mathrm{Al}(\mathrm{OH})_{4}^{-}$ions are transferred into the solution, which quickly becomes saturated. The next stage is so called induction period, in which the release of heat is inhibited and the hydration nuclei appear and grow. After completion of this period massive precipitation of hydrates occurs which is accompanied by significant heat release [5].

Introduction of $5 \%$ of additives into cement system causes acceleration of hydration processes which is manifested in shortening of induction period. Addition of pulverized fly ash is the exception. In case of higher amount of additives (25\%), their influence is more diverse. The accelerating action is displayed by both of fly ashes and also by Portland cement. It may be influence of nucleation action of additive fine grains, but also releasing of ions securing high $\mathrm{pH}$ of environment $(\mathrm{pH}$ of water extract of the additives is above 11). $\mathrm{Na}^{+}$and $\mathrm{K}^{+}$ions liberated from the ashes as well as $\mathrm{Ca}^{2+}$ from Portland cement and fluidized fly ash may accelerate hydration of calcium aluminate cement. Generally, acting of alkalis, coming, e.g. from aggregate, depends on their concentration and temperature, especially when arising products are considered. For example, small concentration of $\mathrm{K}^{+}$ions may accelerate hydration of cement and change mineralogical composition of cement material [14].

In the presence of $25 \%$ of additives, the intensity of heat releasing after induction period is smaller compared to the result for reference sample. It may suggest that, in first hours of hydration, the amount of arising products is lower in the presence of additives despite their accelerate action ("dilution" of cement by material of smaller activity). It is especially visible in the case of pulverized fly ash that suggests its relatively low chemical activity in the initial stages after addition of water into cement. Activity of silicate additives is determined by the rate of penetration of silica into solution. In the case of conventional fly ash its initial low activity is confirmed by a lot of research works devoted to studies on this material as pozzolanic additive into Portland cement composites (e.g. [15]). Grains of pulverized fly ash need some time for dissolving and taking part in chemical reactions. The fluidized fly ash, in contrast to pulverized one, exhibit higher activity [11].

In the case of addition of Portland cement, that is an active hydraulic material, into aluminate cement paste the products of hydration of these two types of cements may arise, i.e. hydrated aluminate phases, $\mathrm{C}-\mathrm{S}-\mathrm{H}$ or $\mathrm{C}-\mathrm{A}-\mathrm{S}-\mathrm{H}$ phases and ettringite.

Basing on presented results one may constater that the course of initial hydration of calcium aluminate cement in the presence of additives is dependent on both their quality and quantity. In the case of addition of Portland cement the above statements are also confirmed by work of other authors [6]. Early hydration of binder composed of calcium aluminate cement and Portland cement depends on quantity proportion of both components. Thus, different products may arise during hydration of these systems and it may be observed using calorimetry measurements.

When the content of calcium aluminate cement is not less than $80 \%$, heat releasing is mainly caused by hydration of this cement. Portland cement also undergoes hydration in this time but this process does not cause separated heat effect on calorimetric curve [8]. It is visible on presented results for cement paste containing 5\% of Portland cement (see Fig. 1a). In case of mixtures rich in Portland cement (not studied in this work) calorimetric curves are similar to result for Portland cement, especially in cases when content of aluminate cement does not exceed $10 \%$ [6].
Fig. 1 Heat evolution curves for cement pastes with 5 and $25 \%$ cement substitution by different materials; a $5 \%$ of additive, $\mathbf{b} 25 \%$ of additive, 1 reference sample $(0 \%$ of additive), 2 addition of pulverized fly ash, 3 addition of fluidized fly ash, 4 addition of Portland cement
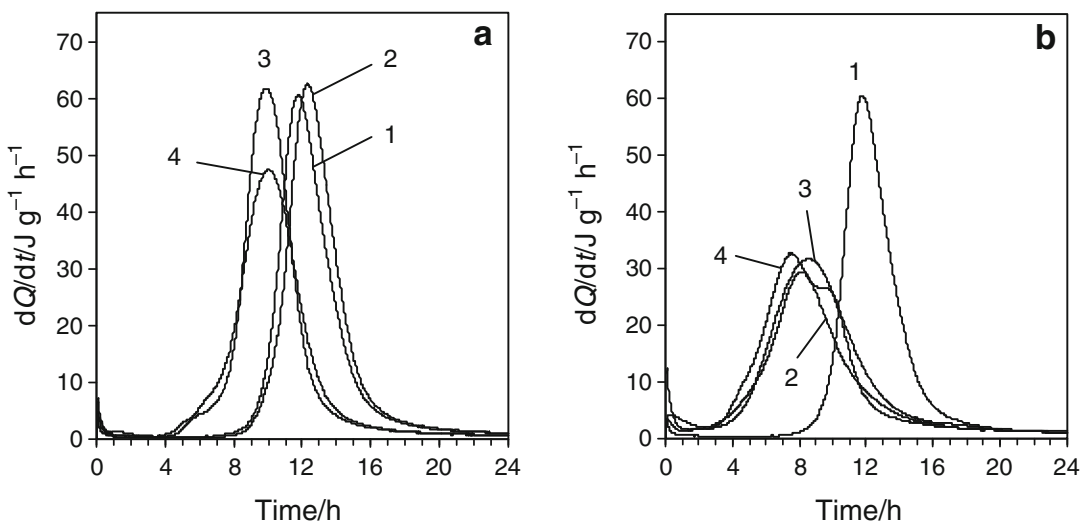
Presented results show that introduction of already $25 \%$ of Portland cement into calcium aluminate cement may change physical and chemical processes. During first minutes of hydration of cement paste containing $25 \%$ of Portland cement, the heat evolution is more intensive than in the case of sample with only $5 \%$ of this additive as well as of reference sample. It may be an effect of release of $\mathrm{SO}_{4}{ }^{2-}$ ions to solution and then formation of ettringite. Moreover $\mathrm{Ca}^{2+}$ ions coming from Portland cement take part in forming of hydrated aluminate phases. As a result the induction period decreases. However, mechanism consisting in acceleration of hydration of both cements should be also taken into consideration, e.g. acceleration the hydration processes of Portland cement as the result of heat released by reacting aluminate cement [6]. In the next period of hydration the reappearance of fast increase of heat evolving, with two maximums on calorimetric curve at about 7.5 and $10 \mathrm{~h}$, is observed. Such shape of calorimetric curve has no confirmation in literature. In the case of binders of similar components proportion as in this report, the authors of works $[6,7,16]$ conclude that general shape of heat release curve is similar to this one obtained for reference sample (i.e. for only calcium aluminate cement, one peak after induction period). Moreover authors of works [16, 17] do not indentify ettringite in such samples. The absence of ettringite may be explained by nonsufficient availability of $\mathrm{SO}_{4}{ }^{2-}$ ions. It is possible, that observed some differences between literature data and results presented in this work may be effect of using of different types of cements and conditions of hardening (e.g. different water/cement ratio, temperature, the way of water addition etc.).

The action similar to Portland cement (especially when its higher amount was considered) may be also shown by fluidized fly ash due to the presence of gypsum and aluminosilicates in its composition. In this situation, however, an additional effect of heat release is not observed. One may expect that complex products of reactions between components of fly ash and aluminates arise, as it was observed by authors of work [3], in which cement pastes made of aluminate cement, fly ash and gypsum were studied.

\section{Thermal analysis}

Detailed interpretation of results obtained for calcium aluminate cement pastes is difficult because of complexity of composition of studied samples. The processes of dehydration of individual compounds overlap. Multistage decomposition of some hydrates may cause arising of compounds that also may be expected in hydration products of the cement. Moreover temperatures of decompositions for particular hydrates, like in the case of other compounds, depend on their degree of crystallinity, mass of sample, conditions of measurements, gas atmosphere, etc. It explains different temperature ranges that are found in literature and ascribed to presence of specific phases. Thus, thermal analysis results should be discussed only as estimated analysis of composition of aluminate cement pastes. However, it does not change the fact, that thermal analysis is often applied by a lot of researches and obtained results may be helpful especially in comparative analysis of influence of additives on hydration process.

The results of thermal analysis received in this work are presented in Figs. 2, 3 and 4. The main mass loss of dehydration of different hydrates occurs up to $500{ }^{\circ} \mathrm{C}$. That it why, this region was only presented for more clear display of the differences in shapes of TG, DTG and DTA curves. Total mass loss occurring up to $500{ }^{\circ} \mathrm{C}$ was assumed as the amount of water bound in hydrates.

Taking into consideration the above mentioned limits, following interpretation of thermal analysis results for samples after 2 days of hydration was accepted (mainly basing on [1]):

- up to $110{ }^{\circ} \mathrm{C}$ (the main maximum on DTG curve at about $80{ }^{\circ} \mathrm{C}$ ) —dehydration of $\mathrm{AH}_{3} \cdot x \mathrm{H}_{2} \mathrm{O}$ gel,

- $110-210^{\circ} \mathrm{C}$ (maximums on DTG for reference sample at about 125 and $200{ }^{\circ} \mathrm{C}$ )-overlapping effect of dehydration of $\mathrm{CAH}_{10}$ and $\mathrm{C}_{2} \mathrm{AH}_{8}$ phases,

- 210-270 ${ }^{\circ} \mathrm{C}$ (DTG maximum at about $240{ }^{\circ} \mathrm{C}$ ) decomposition of $\mathrm{AH}_{3}$ (gibbsite),

- 270-350 ${ }^{\circ} \mathrm{C}$-dehydration of $\mathrm{C}_{3} \mathrm{AH}_{6}$ (very small effect), alternatively $\mathrm{C}_{3} \mathrm{AS}_{3-x} \mathrm{H}_{2 x}$,

- above $700{ }^{\circ} \mathrm{C}$ - decomposition of carbonates (not presented in the figures).

Above processes are accompanied by endothermic effects on DTA curves.

Summarizing, one may conclude, that following compounds are identified in 2-day-old samples of cement pastes: $\mathrm{AH}_{3} \cdot x \mathrm{H}_{2} \mathrm{O}, \mathrm{CAH}_{10}$ and $\mathrm{C}_{2} \mathrm{AH}_{8}$ as well as gibbsite $\mathrm{AH}_{3}$. The presence of $\mathrm{C}_{3} \mathrm{AH}_{6}$ is almost not observed. Relatively low temperatures of maximums of dehydration effects on DTG curves result on the one hand from small sample mass, and on the other hand they may indicate low degree of crystallinity of products arising in initial periods of hydration.

Introduction of additives into cement paste causes quantity and quality differences in hydration products, depending on properties and amounts of the additive.

Smaller differences in shapes of registered curves are observed in case of $5 \%$ of additive (Fig. 2a). The DTG results registered for samples containing $5 \%$ of both of fly ashes are similar to the findings for the reference paste, however, in case of fluidized fly ash slightly greater content 
Fig. 2 TG, DTG and DTA curves for cement pastes with 5 and $25 \%$ cement substitution by different materials (2nd day of hydration); a $5 \%$ of additive, b $25 \%$ of additive, 1 reference sample ( $0 \%$ of additive), 2 addition of pulverized fly ash, 3 addition of fluidized fly ash, 4 addition of Portland cement

Fig. 3 TG, DTG and DTA curves for cement pastes with 5 and $25 \%$ cement substitution by different materials (28th day of hydration); a $5 \%$ of additive, b $25 \%$ of additive, 1 reference sample ( $0 \%$ of additive), 2 addition of pulverized fly ash, 3 addition of fluidized fly ash, 4 addition of Portland cement
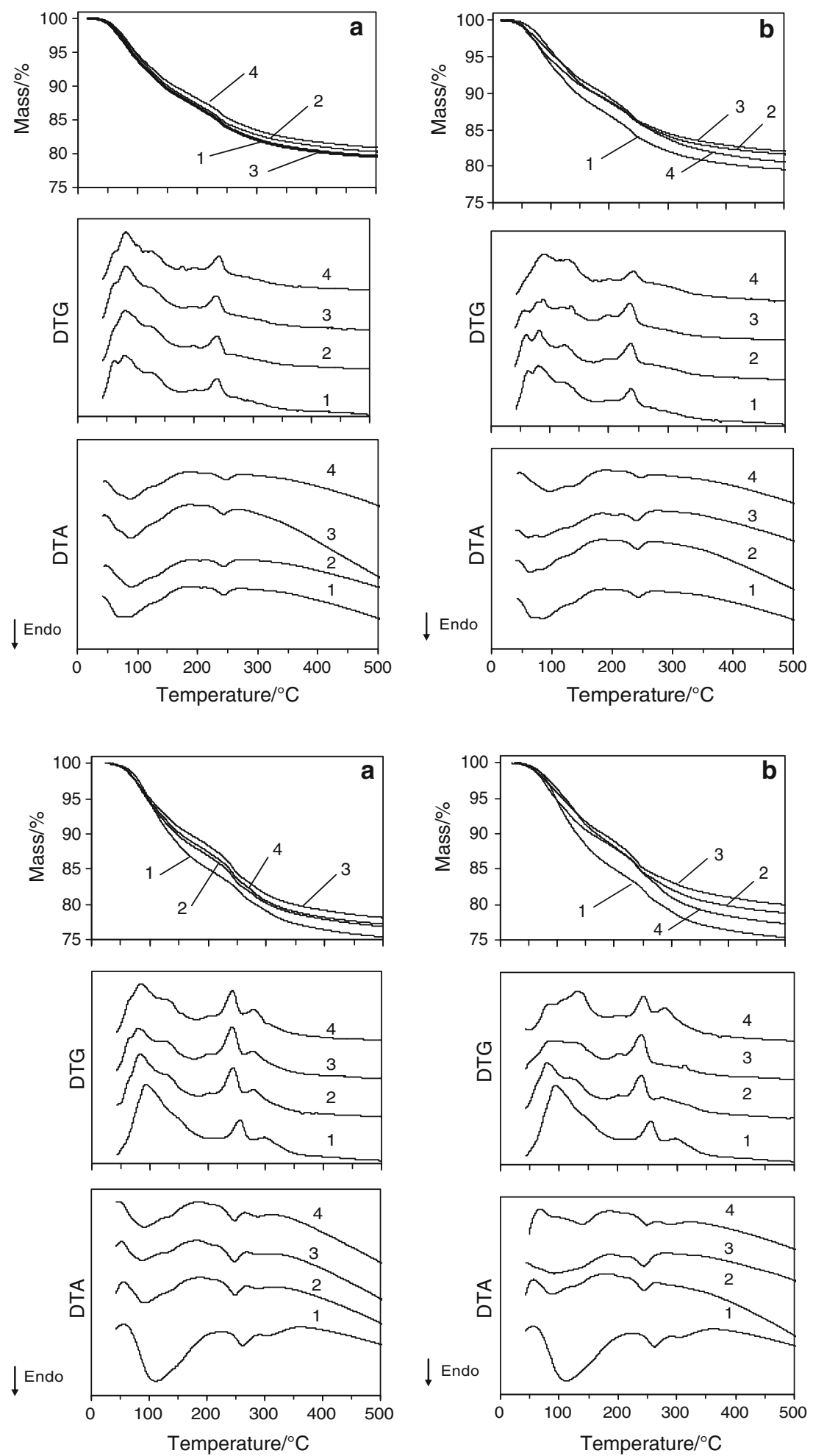

of $\mathrm{AH}_{3} \cdot x \mathrm{H}_{2} \mathrm{O}$ gel is observed. Introduction of very active hydraulic material such as Portland cement causes more differences in arising products. In this case beside maximums on DTG at about 80,200 and $240{ }^{\circ} \mathrm{C}$ also additional effects at about 105 and $180{ }^{\circ} \mathrm{C}$ are visible. Moreover effect registered for the other samples at $125^{\circ} \mathrm{C}$ appears in the form of two peaks at about 115 and $130{ }^{\circ} \mathrm{C}$. In case of $5 \%$ of additives loss of mass up to temperature $500{ }^{\circ} \mathrm{C}$ (Fig. 4), corresponding to the amount of water bound in hydrates, is close to value for reference sample in case of fluidized fly ash and lower for pulverized fly ash and Portland cement addition. 


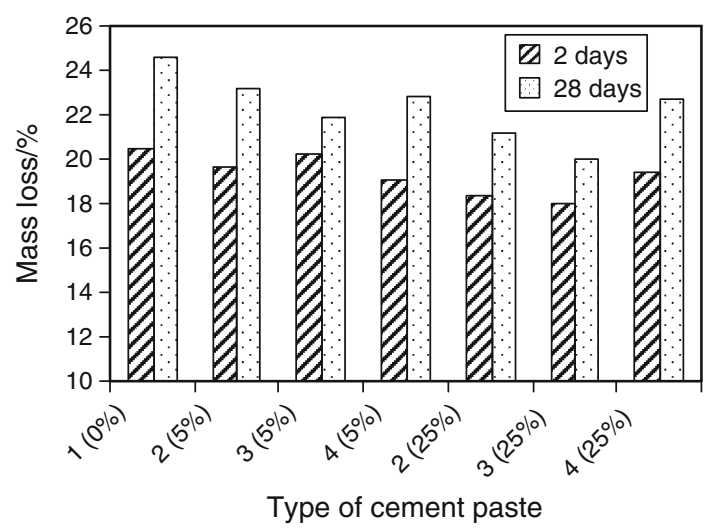

Fig. 4 Mass loss up to temperature $500{ }^{\circ} \mathrm{C}$ for cement pastes with 5 and $25 \%$ cement substitution by different materials (after 2 nd and 28th day of hydration); 1 reference sample ( $0 \%$ of additive), 2 addition of pulverized fly ash, 3 addition of fluidized fly ash, 4 addition of Portland cement

Introduction of higher amounts of additives, i.e. 25\% (Fig. 2b), causes greater differences in quantity and quality of hydration products than in situations when only $5 \%$ is present. In the case of $25 \%$ of pulverized fly ash the shapes of registered curves indicate that hydration products are similar to these, that arise in reference paste and some differences are only in their quantity. Lower mass loss to $500{ }^{\circ} \mathrm{C}$ for the sample containing this fly ash indicates also lower amount of bound water in comparison with reference. It also may confirm low initial activity of this type of additive (see Fig. 4). The greatest quality changes in hydrating systems is caused by addition of $25 \%$ of Portland cement as well as fluidized fly ash. In the case of Portland cement the first effect on DTG is slightly shifted to $90{ }^{\circ} \mathrm{C}$. Then, during the increase of temperature, clear peaks are visible at about 120,130 and $175{ }^{\circ} \mathrm{C}$, respectively. It is probably effect of overlapping of dehydration processes of products of hydration for two cements existing in the system. Like in the case of other samples, the effect of dehydration of gibbsite at about $240{ }^{\circ} \mathrm{C}$ on DTG is observed, and then, from the side of higher temperatures, dehydration of $\mathrm{C}_{3} \mathrm{AH}_{6}$ starts to be visible. It may be an effect of accelerate of aluminate conversion to $\mathrm{C}_{3} \mathrm{AH}_{6}$ as a result of higher content of $\mathrm{Ca}^{2+}$ and alkalis. According to information given in [3] small amount of gypsum also may influence on $\mathrm{C}_{3} \mathrm{AH}_{6}$ formation in this way, that production of ettringite and binding of aluminates in this process is preferred. However, too low amount of gypsum in investigated systems may be insufficient to destabilization of $\mathrm{C}_{3} \mathrm{AH}_{6}$ phase.

It is characteristic that the mass loss at about $480{ }^{\circ} \mathrm{C}$ relating to $\mathrm{Ca}(\mathrm{OH})_{2}$ decomposition is not observed even when $25 \%$ of additive is introduced. It confirms that arising $\mathrm{Ca}(\mathrm{OH})_{2}$ as a product of hydration of Portland cement quickly undergoes further reactions with aluminate phases.

Similar shapes of DTG and DTA curves to these registered for samples containing Portland cement are also observed for the cement pastes with fluidized fly ash addition. It confirms early presumptions about similar influence of these types of materials on aluminate cement hydration. In the case of $25 \%$ of fluidized fly ash beside extreme at about $80{ }^{\circ} \mathrm{C}$, the second effect at about $90{ }^{\circ} \mathrm{C}$ followed by two peaks at about 120 and $135{ }^{\circ} \mathrm{C}$ are also visible on the DTG curve. Probably first products of reactions taking part with components of fluidized fly ash were already produced. Lower mass losses up to $500{ }^{\circ} \mathrm{C}$ for samples containing $25 \%$ of Portland cement or fluidized fly ash indicate, however, lower amounts of water bound in hydrated phases as compared to reference without the additions.

After 28th day of hydration the thermal analysis results exhibit more differences in compositions of the studied cement pastes (Fig. 3). For almost all samples appearance of effect with extreme at about $280{ }^{\circ} \mathrm{C}\left(300{ }^{\circ} \mathrm{C}\right.$ for the reference) was revealed, that may be related to presence of phase $\mathrm{C}_{3} \mathrm{AH}_{6}$. Simultaneously the intensity of effect at about $245{ }^{\circ} \mathrm{C}$ corresponding to dehydration of $\mathrm{AH}_{3}$ increases. Also in the case of 28th day old samples the greater differences in the results, as compared with the reference, are displayed by the samples containing $25 \%$ of Portland cement and fluidized fly ash. The TG, DTG and DTA curves for these samples indicate arising new hydration products in the systems, different from those that are produced in the reference paste. On the contrary, pulverized fly ash does not cause significant differences in quality composition of cement paste. However, in the presence of Portland cement and fluidized fly ash compound silicate-aluminate phases as well as aluminate-sulphate phases are formed. Probably $\mathrm{C}-\mathrm{S}-\mathrm{H}$ phase that is formed in initial stages of hydration undergoes further transformations with participation of hydrated aluminates and $\mathrm{AH}_{3}$. As a result phases type of $\mathrm{C}-\mathrm{A}-\mathrm{S}-\mathrm{H}$, e.g. $\mathrm{C}_{2} \mathrm{ASH}_{8}$ are formed. In the case of $25 \%$ of Portland cement it is confirmed by relatively low content of $\mathrm{AH}_{3}$ compared to increased amount of $\mathrm{C}_{3} \mathrm{AH}_{6}$. It suggests that $\mathrm{AH}_{3}$ released during conversion, that is accelerated in the presence of Portland cement, undergoes further chemical reactions. Moreover silicate ions may incorporation into structure of aluminates. The products, that are formed in the presence of fluidized fly ash during 28 days of hydration, are in some degree different than in the presence of Portland cement, that is confirmed by the shapes of registered curves. The effect related to $\mathrm{C}_{3} \mathrm{AH}_{6}$ is not clearly visible. It may suggest that in the presence of fluidized fly ash conversion is not accelerated as in the case of Portland cement, but it is inhibited. 
Infrared spectroscopy

IR spectra of cement pastes for selected wave numbers regions are presented in Figs. 5 and 6. Additionally in Fig. 7 spectra for dry components are also presented for a comparison.

Comparing the results for the reference cement paste and for dry calcium aluminate cement, one may observe distinct differences resulting from occurring of chemical processes. The bands characteristic for dry cement, i.e. intensive complex band with extreme at about $805 \mathrm{~cm}^{-1}$ corresponding to vibrations of $\mathrm{AlO}_{4}$ groups as well as bands of $\mathrm{AlO}_{6}$ vibrations at about 680 and $640 \mathrm{~cm}^{-1}$ [3], gradually change. The band observed in spectra of cement at about $415 \mathrm{~cm}^{-1}$ shifts to slightly higher values of wave numbers in spectra for cement pastes. For cement pastes containing the additives there are also not observed any bands that may be unequivocally combined with their presence in the samples.

The shapes of all spectra for cement pastes are similar. The following groups of bands may be specified [1]:
Fig. 5 IR spectra for cement pastes with 5 and $25 \%$ cement substitution by different materials (2nd day of hydration); a 5\% of additive, b $25 \%$ of additive, 1 reference sample ( $0 \%$ of additive), 2 addition of pulverized fly ash, 3 addition of fluidized fly ash, 4 addition of Portland cement
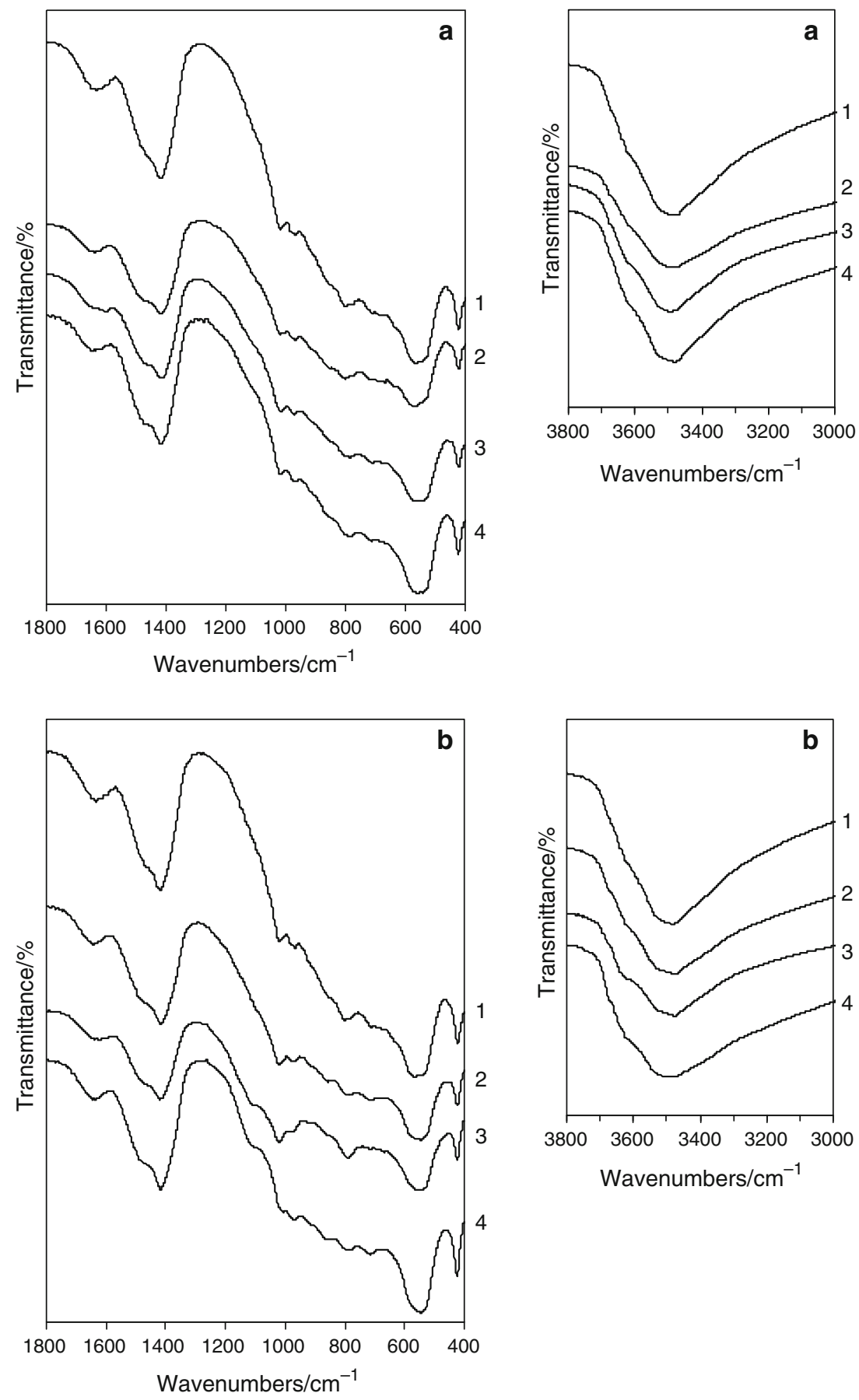
Fig. 6 IR spectra for cement pastes with 5 and $25 \%$ cement substitution by different materials (28th day of hydration); a 5\% of additive, b $25 \%$ of additive, 1 reference sample ( $0 \%$ of additive), 2 addition of pulverized fly ash, 3 addition of fluidized fly ash, 4 addition of Portland cement
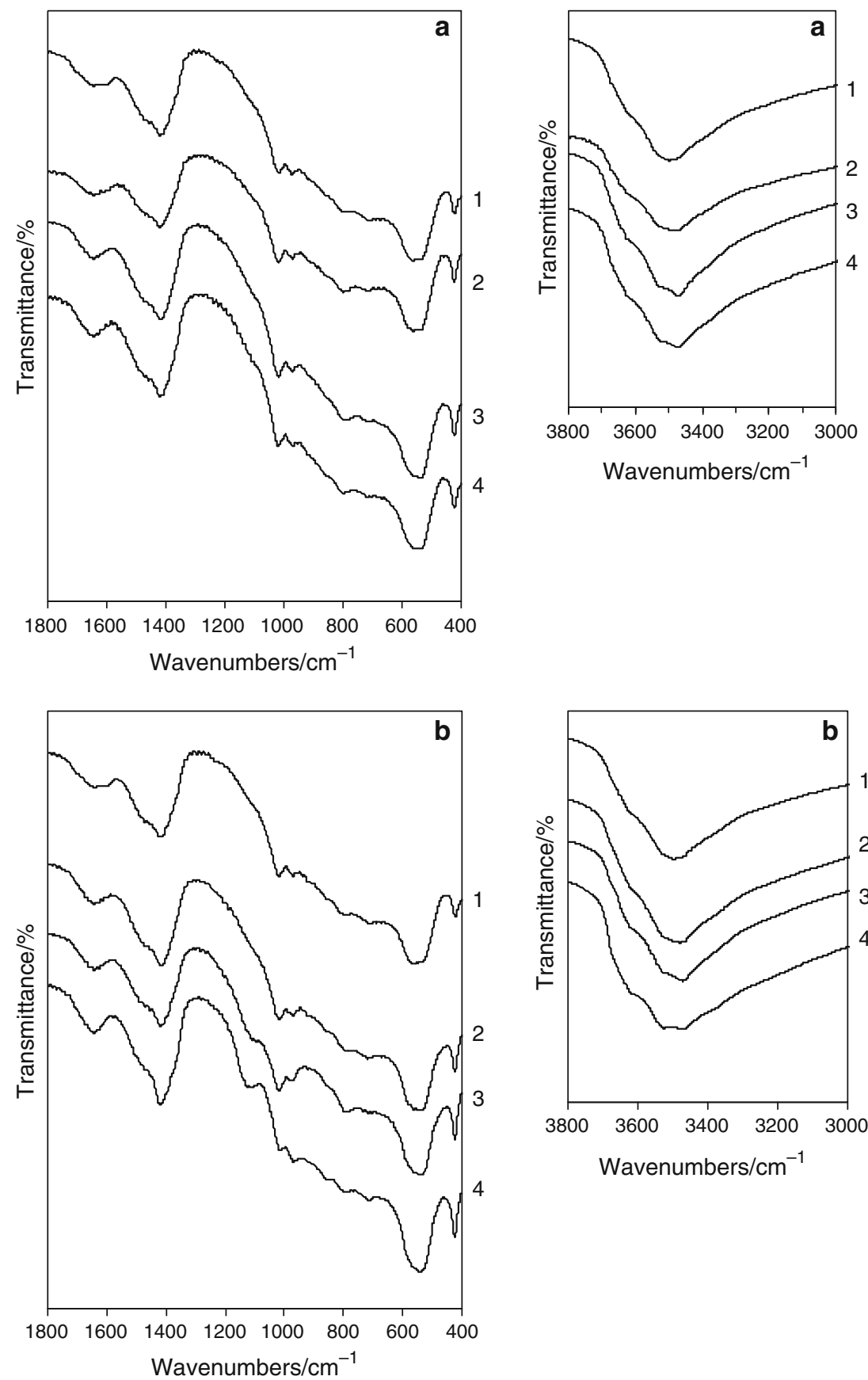

- broad, intensive band in the region of wave numbers of $2500-3700 \mathrm{~cm}^{-1}$, with the extreme at about $3480 \mathrm{~cm}^{-1}$ overlapping bands of $\mathrm{OH}$ vibration in hydrates,

- the band of middle intensity at about $1630 \mathrm{~cm}^{-1}$ bands of bending vibrations of $\mathrm{OH}$ in $\mathrm{HOH}$,

- band of middle intensity at about $1415 \mathrm{~cm}^{-1}$ - the stretching vibrations of $\mathrm{CO}_{3}{ }^{2-}$ in carbonates type of calcite $\left(1415 \mathrm{~cm}^{-1}\right)$, aragonite + vaterite (the band form the side of higher wave numbers),

- overlapping intensive bands: a. at about $1020,965,800 \mathrm{~cm}^{-1}$ — the bands of bending vibrations of $\mathrm{OH}$ in gibbsite, but the band at about $1120 \mathrm{~cm}^{-1}$ may be also related to $\mathrm{Si}-\mathrm{O}$, while the band at about $800 \mathrm{~cm}^{-1}$ to vibrations of $\mathrm{Al}-\mathrm{O}$

b. about $565 \mathrm{~cm}^{-1}$-bands of vibrations of $\mathrm{Al}-\mathrm{O}$.

The broad intensive band of $\mathrm{OH}$ vibrations in region of $2500-3700 \mathrm{~cm}^{-1}$ with the extreme at $3500 \mathrm{~cm}^{-1}$ indicates the presence of $\mathrm{CAH}_{10}$ [14] that probably is the main hydration product. It is confirmed by absence of other bands that could identify individual groups of the 


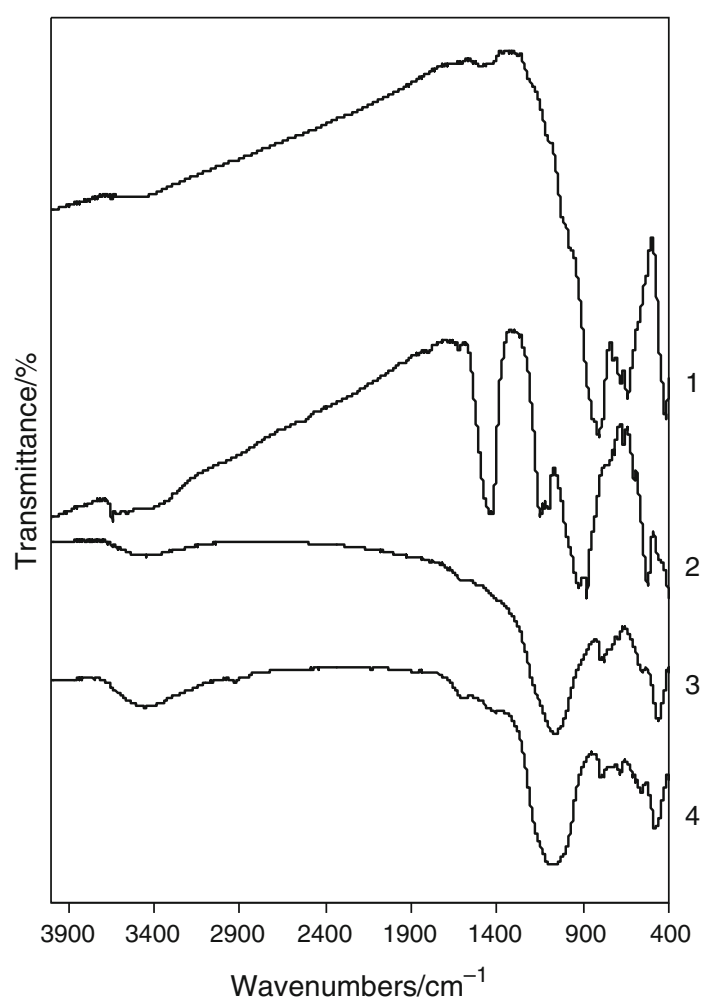

Fig. 7 IR spectra for components of cement pastes; 1 calcium aluminate cement, 2 Portland cement, 3 pulverized fly ash, 4 fluidized fly ash

compounds, e.g. there is not distinct bands of stretching vibrations of $\mathrm{OH}$ in gibbsite or in phases type of $\mathrm{C}_{4} \mathrm{AcH}_{11}$. In case of $25 \%$ of fluidized fly ash and Portland cement one may observe some shoulders by the side of higher wave numbers that may indicate acceleration of chemical processes and thereby more amount of $\mathrm{AH}_{3}$ (gibbsite) formed during hydration. This effect is most of all visible in the spectra for the samples after 28 days of hydration. In this case two extremes at about 3470 and $3525 \mathrm{~cm}^{-1}$ and some shoulder at about $3620 \mathrm{~cm}^{-1}$ separate. Distinct band at about $3665 \mathrm{~cm}^{-1}$, that may confirm the presence of $\mathrm{C}_{3} \mathrm{AH}_{6}$ $[2,3]$, is not visible.

In the region of wave numbers of $1300-500 \mathrm{~cm}^{-1}$ in IR spectra for all cement pastes the bands at about: 1020, 970 and $550 \mathrm{~cm}^{-1}$ are visible. It should be noticed that in case of samples with additives the band at about $970 \mathrm{~cm}^{-1}$ may be also connected with $\mathrm{C}-\mathrm{S}-\mathrm{H}$ phase. When $5 \%$ of additives are considered, the spectra after 2 nd day of hydration are similar to the reference. Greater differences characterize the IR spectra for samples containing higher amount of additives. Following absorption bands are visible for samples containing $25 \%$ of additives: for cement paste with pulverized fly ash-at about 855,785 and $712 \mathrm{~cm}^{-1}$, with fluidized fly ash-about 910, 785, 712 and $670 \mathrm{~cm}^{-1}$, and with Portland cement $-855,785,714 \mathrm{~cm}^{-1}$, respectively.
Moreover in case of samples containing fluidized fly ash and Portland cement a shoulder of band at about $1100 \mathrm{~cm}^{-1}$ is observed. The absorption bands at about 712 and $875 \mathrm{~cm}^{-1}$ with a connection of distinct band at about $1420 \mathrm{~cm}^{-1}$ may be related to vibrations in calcite [18].

In discussed wave numbers region, the result for reference cement paste after 28th day is not significantly different from this one registered after 2 nd day. When $25 \%$ of fluidized fly ash is added some shoulder at $1107 \mathrm{~cm}^{-1}$ is visible both in 2 nd and 28th day of hydration. It may suggest the presence of non-reacted ash in the system (the main band for fluidized fly ash is at about $1080 \mathrm{~cm}^{-1}$ - the vibrations of $\mathrm{Si}(\mathrm{Al})-\mathrm{O}$ in tetrahedral groups [3], see Fig. 7). However, location of this band may also indicate formation of ettringite with the share of $\mathrm{SO}_{4}{ }^{2-}$ ions introduced with the fly ash. Also in case of $25 \%$ of Portland cement similar band is observed. In the second case discussed band appears at about $1110 \mathrm{~cm}^{-1}$ after 2nd day and after 28 days it shifts to about $1120 \mathrm{~cm}^{-1}$ and increases its intensity. The band characteristic for vibrations of $\mathrm{SO}_{4}$ in ettringite may be expected at about $1120 \mathrm{~cm}^{-1}$ [3] thus obtained results may suggest small amount of this compound formed in presence of higher amount of fluidized fly ash and Portland cement. However, complexity of investigated systems causes that unequivocal identification is not possible.

\section{Conclusions}

Received results of hydration of calcium aluminate cement in the presence of different additives allow to draw following conclusions:

1. Hydration of calcium aluminate cement is closely dependent on the type of addition and its amount.

2. Introduction of 5\% of fluidized fly ash or Portland cement causes acceleration of hydration processes (shortening of induction period). Conventional fly ash used in the same amount does not influence significantly kinetics of cement hydration.

3. After introduction of $25 \%$ of studied additions, shortening of induction period ensues independently of their types. Forming of new products is also observed.

4. In the presence of fluidized fly ash and Portland cement in cement paste made of calcium aluminate cement, compound products type of $\mathrm{C}-\mathrm{A}-\mathrm{S}-\mathrm{H}$ beside of typical products of cement hydration arise. The presence of conventional fly ash causes mainly quantity differences in hydration products compared with reference sample.

5. In the case of presence of fluidized fly ash and especially of Portland cement initial activity is dependent on 
transfer of $\mathrm{Ca}^{2+}$ as well as $\mathrm{SO}_{4}{ }^{2-}$ into the solution and probably formation of ettringite. In case of conventional fly ash dissolving of the grains and going of ions into pore solution need more time. Probably this process is faster in case of porous grains of fluidized fly ash. Moreover in case of all used additives other ions, beside of calcium and sulphate ions, releasing into water and also fine grains of these materials influence hydration of cement.

6. Replacement of Portland cement by fluidized fly ash in special binders made of calcium aluminate cement may be alternative for development of fast-setting binders. However, the amount of fly ash and its properties should be optimized. It is possible that for obtaining optimal properties of the binders some additional amount of gypsum should be introduced.

7. Fluidized fly ash used in amount of $25 \%$ of binder mass may effectively reduce the conversion of aluminate.

Above conclusions resulting from initial studies need to be confirmed. It is necessary to perform further investigations of hydration of calcium aluminate cement in the presence of additives (XRD, SEM and others) and of composites obtained on the basis of such two-component binder.

Open Access This article is distributed under the terms of the Creative Commons Attribution Noncommercial License which permits any noncommercial use, distribution, and reproduction in any medium, provided the original author(s) and source are credited.

\section{References}

1. Hidalgo A, García JL, Cruz Alonso M, Fernández L, Andrade C. Microstructure development in mixes of calcium aluminate cement with silica fume or fly ash. J Therm Anal Calorim. 2009;96:335-45.

2. Hidalgo López A, García Calvo JL, García Olmo J, Petit S, Cruz Alonso M. Microstructural evolution of calcium aluminate cements hydration with silica fume and fly ash additions by scanning electron microscopy, and mid and near-infrared spectroscopy. J Am Ceram Soc. 2008;91:1258-65.

3. Fernández-Carrasco L, Vázquez E. Reactions of fly ash with calcium aluminate cement and calcium sulphate. Fuel. 2009;88:1533-8.

4. Quillin K, Osborne G, Majumdar A, Singh B. Effects of w/c ratio and curing conditions on strength development in BRECEM concretes. Cem Concr Res. 2001;31:627-32.

5. Pacewska B, Wilińska I, Bukowska M. Calorimetric investigations of the influence of waste aluminosilicate on the hydration of different cements. J Therm Anal Calorim. 2009;97:61-6.

6. Ping $\mathrm{Gu}$, Beaudoin JJ. A conduction calorimetric study of early hydration of ordinary Portland cement/high alumina cement pastes. J Mater Sci. 1997;32:3875-81.

7. Gawlicki M, Nocuń-Wczelik W, Bạk Ł. Calorimetry in the studies of cement hydration. Setting and hardening of Portland cement-calcium aluminate cement mixtures. J Therm Anal Calorim. 2010;100:571-6.

8. Hewlett PC, editor. Lea's chemistry of cement and concrete. 4th ed. London: Arnold; 1998.

9. Rivas Mercury JM, Turrillas X, de Aza AH, Pena P. Calcium aluminates hydration in presence of amorphous $\mathrm{SiO}_{2}$ at temperatures below $90^{\circ} \mathrm{C}$. J Solid State Chem. 2006;179:2988-97.

10. Giergiczny Z. Popioły lotne z dużą zawartością wapnia (in Polish). Cement Wapno Beton. 2005;55:271-82.

11. Pacewska B, Blonkowski G, Wilińska I. Studies on the pozzolanic and hydraulic properties of fly ashes in model systems. J Therm Anal Calorim. 2008;94:469-76.

12. Information of Górkal cement producer. www.gorka.com.pl. Product description calcium aluminate cement Górkal 40. 2009. http://www.gorka.com.pl/pdf/spec_g40_en.pdf. Accessed Sept 2010.

13. Poznański J. Computer software for processing of data obtained from calorimeter. 2005.

14. Fernández-Carrasco L, Blanco-Varela MT, Puertas F, Vázquez T, Glasser FP, Lachowski E. Hydration of high alumina cement in the presence of alkalis. Adv Cem Res. 2000;12:143-52.

15. Rahhal V, Talero R. Influence of two different fly ashes on the hydration of Portland cements. J Therm Anal Calorim. 2004;78: 191-205.

16. Ping Gu, Beaudoin JJ, Quinn EG, Myers RE. Early strength development and hydration of ordinary Portland cement/calcium aluminate cement pastes. Adv Cem Bas Mater. 1997;6:53-8.

17. Garcés P, Garcia Alcocel E, Garcia Andreu C. Hydration characteristics of high alumina cement/Portland cement mixtures. ZKG Int. 1998;11:646-9.

18. Blanco-Varela MT, Martínez-Ramírez S, Vázquez T, SánchezMoral S. Role of alkalis of aggregate origin in the deterioration of CAC concrete. Cem Concr Res. 2005;35:1698-704. 